\title{
Sitagliptin/Simvastatin: a first combination tablet to treat type 2 diabetes and hypercholesterolemia - a review of its characteristics
}

This article was published in the following Dove Press journal:

Vascular Health and Risk Management

II February 2015

Number of times this article has been viewed

\section{Wijdan H Ramadan \\ Wissam K Kabbara}

Department of Pharmacy Practice, School of Pharmacy, Lebanese American University, Byblos, Lebanon
Background: The purpose of this study was to review the current literature and information on the combination product Juvisync ${ }^{\mathrm{TM}}$ (sitagliptin + simvastatin), which was approved by the US Food and Drug Administration in October 2011.

Methods: PubMed (2001-2014) was searched for primary and review articles on sitagliptin, simvastatin, or the combination product. Drug manufacturing data and product labeling were also used. Studies of simvastatin, sitagliptin, or the combination were screened and analyzed to include relevant and recent papers. Selected English language trials were limited to those with human subjects and included both safety and efficacy outcomes.

Results: When compared with glipizide as add-on therapy to metformin, sitagliptin was noninferior but had lower rates of hypoglycemia and weight gain. In addition, when compared with insulin glargine, sitagliptin was less effective in decreasing glycosylated hemoglobin, but was associated with significantly lower rates of hypoglycemia. Further, trials have shown a beneficial effect of using statins in patients with diabetes mellitus with regard to decreasing cardiovascular risk, regardless of baseline lipid levels or the presence of a cardiac disease. Both medications have also demonstrated an acceptable side effect profile. However, caution is needed when coadministering with any drug that may increase simvastatin levels to reduce the risk of myopathy and rhabdomyolysis.

Conclusion: Juvisync should be used in patients requiring both sitagliptin and simvastatin. Both agents have shown good efficacy and acceptable safety profiles. Sitagliptin is a good option for diabetic patients to improve glycemic control with a lower risk of hypoglycemia and weight gain.

Keywords: simvastatin, sitagliptin, Juvisync ${ }^{\mathrm{TM}}$, diabetes mellitus, hypercholesterolemia

\section{Introduction}

Type 2 diabetes is a chronic metabolic disease characterized by insulin resistance, where muscle and adipose cells are not able to respond adequately to normal levels of insulin. According to the Centers for Disease Control and Prevention, the number of people with type 2 diabetes mellitus (DM) in the USA is now estimated to be 26 million and projected to triple by the year 2050. ${ }^{1}$ Diabetes is known as a "silent killer" since patients die more often from chronic complications rather than hyperglycemic crisis if uncontrolled. The disease damages the eyes (retinopathy), the kidneys (nephropathy), and the nervous system (neuropathy). It also has macrovascular complications, including peripheral vascular disease, cerebrovascular disease (CVD), and coronary heart disease (CHD). Therefore, the main goal of diabetes management and control is to minimize
Correspondence: Wijdan H Ramadan Department of Pharmacy Practice, School of Pharmacy, Lebanese American University, PO Box 36-F53, Byblos, Lebanon

Tel +96I 9547294 ext 2267

Emailwramadan@lau.edu.lb 
and delay its complications. However, there has been debate on how much is considered appropriate control. The American Diabetes Association recommends a glycemic target of a glycosylated hemoglobin $\left(\mathrm{HbA}_{1 \mathrm{c}}\right)<7 \%$, while the American Association of Clinical Endocrinologists has a stricter goal of an $\mathrm{HbA}_{1 \mathrm{c}}<6.5 \%{ }^{2,3}$ Studies have shown that glycemic control in DM slows the progression of microvascular complications. ${ }^{4}$ Further, in a 10-year follow-up of patients in the UK Prospective Diabetes Study, those with a lower glycemic target $\left(\mathrm{HbA}_{1 \mathrm{c}}<7 \%\right)$ had a reduced risk of cardiovascular events versus those with a higher target $\left(\mathrm{HbA}_{1 \mathrm{c}}<7.9 \%\right){ }^{5}$ However, results from the ADVANCE trial that included 11,140 patients with type 2 diabetes were different. After an average of 5 years of follow-up, intensive control $\left(\mathrm{HbA}_{1 \mathrm{c}}\right.$ $<6.5 \%$ ) reduced the incidence of combined major macrovascular and microvascular events by $10 \%$ (hazards ratio [HR] $0.9 ; 95 \%$ confidence interval $[\mathrm{CI}] 0.82-0.98 ; P=0.01$ ), but there was no significant difference in major macrovascular events (HR 0.94; 95\% CI 0.84-1.06; $P=0.32$ ), death from cardiovascular causes (HR 0.88; 95\% CI 0.74-1.04; $P=0.12$ ), or death from any cause (HR 0.93; 95\% CI 0.83-1.06; $P=0.28$ ). In addition, severe hypoglycemia was more common in the intensive control group (HR 1.86; 95\% CI 1.42-2.40; $P<0.001){ }^{6}$ Therefore, the glycemic target should be individualized after weighing the microvascular benefits versus the risks of hypoglycemia and weight gain.

Sitagliptin, a dipeptidyl peptidase (DPP)-4 inhibitor, showed efficacy similar to that of glipizide in a clinical trial but had a lower risk of hypoglycemia. ${ }^{7}$ Vildagliptin, another DPP-4 inhibitor, showed efficacy similar to that of thiazolidinediones, but without weight gain. ${ }^{8}$ This has made DPP-4 inhibitors promising agents when add-on therapy is needed to maximize glycemic control with a lower risk of hypoglycemia and weight gain.

Having no proof as yet that glycemic control can significantly decrease macrovascular complications, attention has been focused on other means of prevention, especially given that cardiovascular diseases are considered the major cause of morbidity and mortality in DM. Other risk factors for CVD such as hypertension and dyslipidemia usually coexist with DM. Nevertheless, DM is always considered a coronary artery disease risk equivalent. Therefore, the target low-density lipoprotein (LDL) cholesterol level in diabetic patients is $<100 \mathrm{mg} / \mathrm{dL}(2.60 \mathrm{mmol} / \mathrm{L})$, and preferably $<70 \mathrm{mg} / \mathrm{dL}(1.8 \mathrm{mmol} / \mathrm{L})$. Lifestyle modification is indicated in all DM patients. In patients with overt CVD or who are more than 40 years of age and have other risk factors for CVD, statins should be added to lifestyle therapy regard- less of baseline lipid levels. ${ }^{9-11}$ Trials have shown a linear relationship between LDL cholesterol concentration and relative CVD risk; thus, any reduction in LDL cholesterol levels would have a similar relative reduction in CVD risk. ${ }^{11-14}$ For patients aged 40 years or younger, addition of a statin should be considered if LDL cholesterol remains $>100 \mathrm{mg} / \mathrm{dL}$ and in those with several CVD risk factors. ${ }^{9-11}$

Juvisync $^{\mathrm{TM}}$, a medication approved by the US Food and Drug Administration (FDA), is a combination of sitagliptin and simvastatin in one pill. It was approved in October 2011 and is manufactured by MSD International $\mathrm{GmbH}$ for Merck and Co. ${ }^{15}$ Sitagliptin phosphate monohydrate is described chemically as 7-[(3R)-3-amino-1-oxo-4-(2,4,5-trifluorophenyl)butyl]5,6,7,8-tetrahydro-3-(trifluoromethyl)-1,2,4-triazolo[4,3-a] pyrazine phosphate $(1: 1)$ monohydrate, with the structural formula shown in Figure $1 .{ }^{16}$ Simvastatin is butanoic acid, 2,2-dimethyl-, 1,2,3,7,8,8a-hexahydro-3,7-dimethyl-8-[2(tetrahydro-4-hydroxy-6-oxo-2H-pyran-2-yl)-ethyl]-1naphthalenyl ester, $\left[1 S\right.$-[1 $\left.\left.\alpha, 3 \alpha, 7 \beta, 8 \beta\left(2 S^{*}, 4 S^{*}\right),-8 \mathrm{a} \beta\right]\right]$, with the structural formula shown in Figure $2 .{ }^{16}$ The combination pill is indicated for patients requiring both medications, and is considered have significant $\mathrm{HbA}_{1 \mathrm{c}}$-lowering ability and cardiovascular benefits as well. The objective of this article is to provide an overview of sitagliptin and simvastatin used separately and in combination, which led to the development of Juvisync.

\section{Methods for selection and assessment of the literature}

PubMed (2001-2014) was searched for primary literature and review articles on sitagliptin, simvastatin, or the combination. Mainly clinical trials about each active ingredient of Juvisync and their combination were identified, in addition to reviews, meta-analysis, case reports involving each ingredient individually or in combination, and guidelines for diabetes and lipid-lowering agents. However, we did not find any clinical efficacy studies comparing Juvisync with sitagliptin and simvastatin as separate tablets. The search was limited to human studies published in the English language and included both

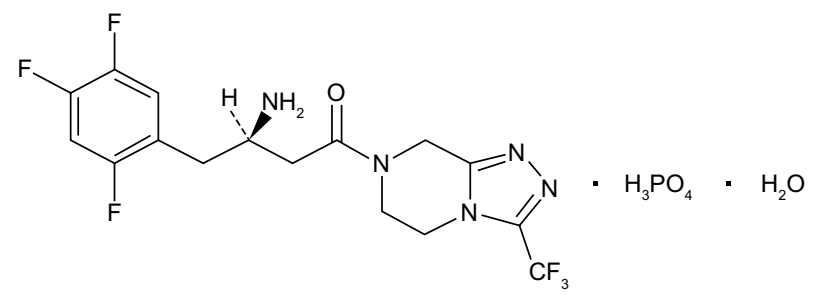

Figure I Structural formula for sitagliptin. 


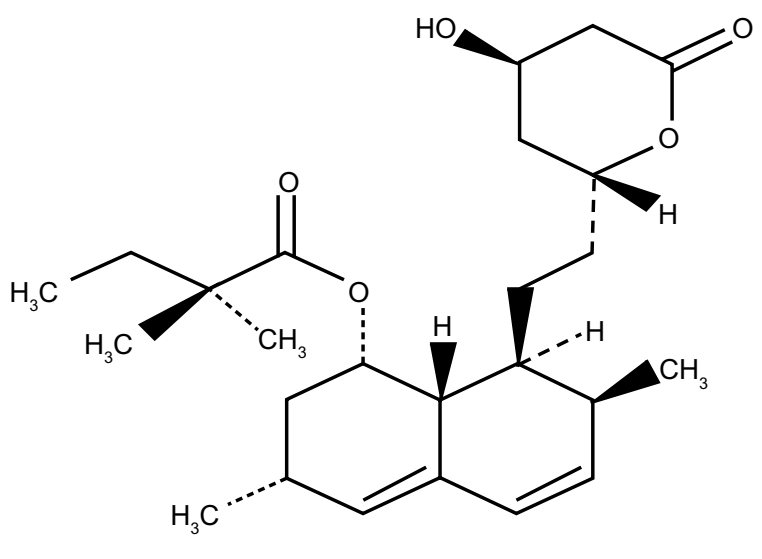

Figure 2 Structural formula for simvastatin.

safety and efficacy outcomes. Manufacturing data and product labeling were also used.

\section{Pharmacology}

Sitagliptin, a DPP-4 inhibitor, is an oral antidiabetic agent that acts by slowing the inactivation of incretin hormones such as glucagon-like peptide-1 and glucose-dependent insulinotropic polypeptide, thereby increasing their action. These hormones are a part of the body's physiological system for glucose homeostasis. Their secretion by the intestines is increased in response to elevated blood glucose levels following a meal. Glucagon-like peptide-1 and glucosedependent insulinotropic polypeptide then act on the pancreas to increase synthesis and release of insulin as well as decreasing secretion of glucagon and release of glucose from the liver; however, these hormones are rapidly deactivated by the DPP-4 enzyme. Thus, by selectively inhibiting this enzyme, sitagliptin increases insulin release and decreases that of glucagon in a glucose-dependent manner. ${ }^{16-18}$ this property makes sitagliptin unique among the antidiabetic agents.

Simvastatin is a prodrug that is hydrolyzed in the body to its active form, $\beta$-hydroxyacid. It acts by inhibiting the hepatic enzyme HMG-CoA reductase that is required for the rate-limiting step in the biosynthesis of cholesterol, leading to a decrease in intracellular cholesterol concentrations. The liver then compensates by increasing the number of LDL receptors on its surface, resulting in increased clearance of LDL. It decreases not only LDL, but triglycerides, intermediate-density lipoprotein, and very-LDL as well, and increases high-density lipoprotein. ${ }^{16}$

\section{Pharmacokinetics}

Bioequivalence studies in healthy subjects show that Juvisync is bioequivalent to coadministration of sitagliptin and simvastatin as separate tablets. ${ }^{19}$ Important pharmacokinetic information on sitagliptin and simvastatin is shown in Table $1 .{ }^{16,18,20}$

Sitagliptin and simvastatin do not have a clinically meaningful pharmacokinetic interaction. A randomized, open-label, crossover study assessing the effect of sitagliptin on the pharmacokinetics of simvastatin showed no statistically significant difference in the kinetics of simvastatin in the combination versus simvastatin alone. Therefore, there is no need to adjust the dose of simvastatin when it is coadministered with sitagliptin. ${ }^{21}$

\section{Clinical trials \\ Sitagliptin}

Several studies have demonstrated the efficacy and safety of sitagliptin. In a 24-week study, the efficacy and safety of sitagliptin was assessed in 441 patients with type $2 \mathrm{DM}$ who were not controlled on glimepiride alone or combined with metformin. The primary outcome (change in $\mathrm{HbA}_{1 \mathrm{c}}$ from baseline to 24 weeks) was decreased by $0.74 \%(P<0.001)$ in those who received sitagliptin when compared with placebo. In those on the combination of metformin and glimepiride, sitagliptin reduced the $\mathrm{HbA}_{1 \mathrm{c}}$ by $0.89 \%$ relative to placebo. In those on glimepiride alone, sitagliptin decreased $\mathrm{HbA}_{1 \mathrm{c}}$ by $0.57 \%$ relative to placebo. However, sitagliptin did have a slightly higher risk of hypoglycemia and weight gain. ${ }^{22}$ In a similar study that assessed the efficacy and safety of combining sitagliptin with a low-dose sulfonylurea, the change in $\mathrm{HbA}_{\mathrm{lc}}$ was $0.8 \%(95 \% \mathrm{CI}-0.9$ to $0.68, P<0.001){ }^{23}$

Sitagliptin was also compared to glipizide as add-on therapy to metformin in uncontrolled patients. In this 52-week study, 1,172 patients were randomized to addition of sitagliptin $100 \mathrm{mg}$ daily or glipizide $5 \mathrm{mg}$ daily to metformin.

Table I Pharmacokinetics

\begin{tabular}{lllll}
\hline & Absorption & Distribution & Metabolism & Elimination \\
\hline Simvastatin & $\mathrm{T}_{\max } 4$ hours & $95 \%$ bound to & Undergoes extensive first-pass & $60 \%$ eliminated in the feces; I3\% in the urine; \\
& Bioavailability $<5 \%$ & plasma proteins & metabolism in the liver via CYP3A4 & $27 \%$ eliminated through other mechanisms \\
Sitagliptin & $\mathrm{T}_{\max } \mathrm{I}-4$ hours & $38 \%$ bound to & Minimally metabolized via CYP3A4 & $87 \%$ eliminated in the urine (79\% as unchanged \\
& Bioavailability $87 \%$ & plasma proteins & and CYP2C8 to inactive metabolites & drug, 8\% as metabolites); I3\% in feces \\
\hline
\end{tabular}

Abbreviations: $\mathrm{T}_{\max }$, time to peak plasma concentration; CYP, cytochrome P450. 
The results showed that sitagliptin was noninferior to glipizide in reducing $\mathrm{HbA}_{1 \mathrm{c}}$. However, hypoglycemia was significantly worse $(P<0.001)$ with glipizide $(32 \%)$ than with sitagliptin (5\%). Further, sitagliptin led to weight loss versus weight gain with glipizide. ${ }^{7}$

Sitagliptin was also compared with insulin. EASIE was a 6-month study comparing sitagliptin with insulin glargine in patients not controlled on metformin. Although the mean decrease in $\mathrm{HbA}_{1 \mathrm{c}}$ was greater on insulin glargine $(-1.72 \%)$ than on sitagliptin $(-1.13 \% ; P<0.0001)$, there were significantly more hypoglycemic events on insulin glargine (4.21 versus 0.5 events per patient-year, $P<0.0001) .{ }^{25}$ In another 24-week study, 641 patients with type 2 diabetes were randomized to assess the efficacy of sitagliptin as add-on to insulin therapy. Sitagliptin provided significant improvements in $\mathrm{HbA}_{1 \mathrm{c}}$ when compared with placebo. However, there were more hypoglycemic events in patients treated with sitagliptin. ${ }^{16}$

\section{Simvastatin}

In the subgroup analysis of diabetes in the Heart Protection Study, patients were randomized to receive either simvastatin $40 \mathrm{mg}$ daily or placebo. The primary outcome was the first post-trial incidence of major coronary events and vascular events. The results showed a significant relative risk reduction for the primary outcome. There was a $20 \%$ reduction in risk of coronary events and a $37 \%$ reduction in nonfatal myocardial infarction. Diabetic patients without CHD were examined for primary prevention, and the results showed a $33 \%$ relative risk reduction for major vascular events $(P=0.0003)$; the results were not affected by duration of diabetes or extent of glycemic control. In addition, the reduction in risk of the primary outcome was not affected by baseline LDL level. In the subgroup of diabetic patients with baseline $\mathrm{LDL}<116 \mathrm{mg} / \mathrm{dL}$, the relative risk reduction for major vascular events remained significant $(27 \%, P=0.0007){ }^{13,14,26}$

CARDS is another study that assessed statin use specifically in type 2 diabetes. It assessed the efficacy of low-dose atorvastatin (10 mg daily) for primary prevention of CVD in patients with type 2 DM. The primary outcome was a composite of the first occurrence of either an acute CHD event, stroke, or coronary revascularization. The primary outcome occurred in $5.8 \%$ of the atorvastatin group versus $9 \%$ of the placebo group (HR $0.63 ; 95 \%$ CI $0.48-0.83 ; P=0.001$ ), with a $37 \%$ relative risk reduction. Tests for heterogeneity of results for baseline lipid levels, $\mathrm{HbA}_{1 \mathrm{c}}$, albuminuria, smoking status, or systolic blood pressure were not significant. ${ }^{12}$ Atorvastatin $20 \mathrm{mg}$ daily was also studied in 1,255 patients with type 2 DM on hemodialysis. The primary outcome was a composite of cardiac death, nonfatal myocardial infarction, and stroke. Atorvastatin caused an $8 \%$ relative risk reduction for the composite outcome; however, this was not statistically significant (relative risk $0.92 ; 95 \%$ CI $0.77-1.1 ; P=0.37$ ). This study could not show a significant effect of atorvastatin on cardiovascular events in hemodialysis patients. ${ }^{27}$

In a diabetic subgroup analysis of the LIPID trial, 6 years of treatment with pravastatin $40 \mathrm{mg}$ daily led to a $24 \%$ relative risk reduction for $\mathrm{CHD}(P<0.001) .{ }^{28} \mathrm{~A}$ meta-analysis of 58 trials showed the highest LDL-lowering ability for rosuvastatin $80 \mathrm{mg}(60 \%)$, followed by atorvastatin $80 \mathrm{mg}$ (55\%) and simvastatin $40 \mathrm{mg}(40 \%)$. It also showed that for each $1 \mathrm{mmol} / \mathrm{L}$ reduction in LDL, the risk of ischemic heart disease was decreased by $11 \%$ in the 1 st year, $24 \%$ in the 2 nd year, $33 \%$ from the 3 rd to 5 th year, and $36 \%$ thereafter $(P<0.001){ }^{29}$

Another analysis compared three statins (atorvastatin, simvastatin, and pravastatin) using eight randomized placebocontrolled trials for long-term cardiovascular prevention. Statistical assessment showed only minor heterogeneity in the effect sizes of the trials. The results showed that the three statins reduced lipid levels to a similar degree. Moreover, no statistically significant difference was found with regard to fatal CHD, nonfatal myocardial infarction, stroke, cardiovascular death, or all-cause mortality. ${ }^{30}$ However, a large metaanalysis including 170,255 patients from 76 randomized trials assessing the efficacy and safety of statins for cardiovascular disease showed an increased risk of new-onset diabetes (odds ratio $1.09 ; 95 \% \mathrm{CI} 1.02-1.17 ; P=0.001)$ and $11 \%$ of these cases were attributed to statin therapy itself $\left(I^{2}=11 \%\right){ }^{31}$

In light of this finding, an analysis of the JUPITER trial was done to weigh the benefits versus risks of using statins for primary prevention. In individuals with one or more risk factors for DM (metabolic syndrome, impaired fasting glucose, body mass index $>30, \mathrm{HbA}_{1 \mathrm{c}}>6 \%$ ), rosuvastatin led to a $39 \%$ reduction in the primary endpoint, ie, composite of myocardial infarction, stroke, hospital admission due to unstable angina, arterial revascularization, or cardiovascular death (HR 0.61; 95\% CI 0.47-0.79; $P=0.0001$ ), a 36\% reduction in risk of venous thromboembolism (HR 0.64; 95\% CI $0.39-1.06 ; P=0.08)$, and a $17 \%$ reduction in total mortality (HR $0.83 ; 95 \%$ CI $0.64-1.07 ; P=0.15$ ). On the other hand, it also led to a $28 \%$ increase in diabetes (HR 1.28; $95 \%$ CI $1.07-1.54 ; P=0.01)$. For patients with no major risk factors for diabetes, rosuvastatin led to a $52 \%$ reduction in the primary endpoint (HR 0.48; 95\% CI 0.33-0.68; $P=0.0001$ ), a $53 \%$ reduction in venous thromboembolism (HR 0.47 ; 
95\% CI $0.21-1.03 ; P=0.05)$, and a $22 \%$ reduction in total mortality (HR 0.78; 95\% CI 0.59-1.03; $P=0.08$ ). However, it did not cause any increase in diabetes (HR 0.99; 95\% CI $0.45-2.21 ; P=0.99)$. Thus, for patients with pre-existing major risk factors for diabetes, for every 54 cases of newonset diabetes, a total of 134 vascular events or deaths were avoided. As for those with no risk factors for diabetes, a total of 86 vascular events or deaths were avoided with no new cases of diabetes. ${ }^{32}$

There have been no clinical efficacy studies comparing Juvisync with sitagliptin and simvastatin administered as separate tablets, and no ongoing clinical trials with Juvisync are currently registered by the FDA.

\section{Contraindications/adverse events/ precautions/drug interactions Contraindications}

Contraindications to the use of Juvisync include any history of serious hypersensitivity to sitagliptin or simvastatin, active liver disease or any persistent unexplained elevation in liver enzymes, and pregnancy and lactation. In addition, Juvisync is contraindicated for coadministration with gemfibrozil, cyclosporine, danazol, or any strong cytochrome P450 3A4 inhibitor. ${ }^{16,19}$

\section{Adverse events}

The most common side effects of sitagliptin seen in the clinical trials were upper respiratory tract infection, nasopharyngitis, and headache. Hypoglycemia was also seen when added to insulin or sulfonylureas. ${ }^{16}$ The most common side effects of simvastatin were myalgia, headache, abdominal pain, constipation, and nausea. ${ }^{16}$

\section{Precautions}

Post-marketing reports have been published on the incidence of acute pancreatitis in patients on sitagliptin. ${ }^{33,34}$ However, it remains unknown whether sitagliptin actually does increase the risk of acute pancreatitis. A retrospective cohort study of 786,656 patients was performed with the help of a large medical and pharmacy claims database. The incidence of acute pancreatitis in the nondiabetic control, diabetic control, exenatide, and sitagliptin groups was 1.9, 5.6, 5.7, and 5.6 cases, respectively, per 1,000 patient years. The risk was significantly higher in the combined diabetic groups than in the nondiabetic control group (adjusted HR 2.1; 95\% CI 1.7-2.5). The risk of acute pancreatitis was similar in the sitagliptin group versus the diabetic control group (HR 1.0; 95\% CI 0.7-1.3). Thus, this study did show an increased incidence of acute pancreatitis in diabetic patients versus nondiabetic patients, but did not find a causal relationship between sitagliptin and acute pancreatitis. ${ }^{35}$

In addition, a further warning for sitagliptin includes a higher risk of hypoglycemia when combined with insulin or sulfonylureas. ${ }^{16,22,23}$ Therefore, adjustment of the dose of insulin or sulfonylureas is needed when combining these agents with Juvisync.

The main label warnings for simvastatin are the risk of myopathy, rhabdomyolysis, and liver enzyme abnormalities. In the SEARCH trial, which compared the safety and efficacy of simvastatin $80 \mathrm{mg}$ versus $20 \mathrm{mg}$ in patients surviving myocardial infarction, myopathy developed in $0.9 \%$ of the patients receiving the $80 \mathrm{mg}$ dose versus only $0.03 \%$ of those receiving the $20 \mathrm{mg}$ dose (relative risk 26.6; $95 \%$ CI 6.5-109.3; $P<0.0001)$. Rhabdomyolysis developed in $0.4 \%$ at the $80 \mathrm{mg}$ dose and in none at the $20 \mathrm{mg}$ dose. ${ }^{36,37}$ Thus, the risk of myopathy and rhabdomyolysis appears to be dose-dependent. Although Juvisync does not contain an $80 \mathrm{mg}$ dose for simvastatin, caution is still warranted.

There has also been a case report of a patient with chronic kidney disease who developed acute kidney injury and rhabdomyolysis after receiving high doses of sitagliptin and simvastatin. The patient was already at home on simvastatin $80 \mathrm{mg}$ daily and ezetimibe $10 \mathrm{mg}$ daily, both of which increase the risk of rhabdomyolysis. The patient was started on sitagliptin $50 \mathrm{mg} 6$ weeks prior to presentation and was titrated to $100 \mathrm{mg}$ daily 3 weeks later. One week after the dose titration, the patient started to have muscle pain in the thighs. Upon admission and diagnosis of acute kidney injury and rhabdomyolysis, all drugs that could have led to this problem were discontinued, including sitagliptin, simvastatin, and ezetimibe. The patient's kidney function recovered in a week, and all medications were resumed except the aforementioned three drugs. Simvastatin was replaced with lovastatin, with no recurrence of rhabdomyolysis. ${ }^{38}$

Simvastatin, like all other statins, caused elevations in liver enzymes (more than three times the upper normal limit) in almost $1 \%$ of patients who received it in clinical trials. ${ }^{16}$ Laboratory testing for liver enzymes is required upon initiation of Juvisync and whenever clinically needed.

As discussed earlier, recent studies have suggested that statin use may be linked to occurrence of new-onset diabetes. However, analysis of the JUPITER trial showed that this was only significant in patients with pre-existing risk factors for diabetes, and that the cardioprotective benefits outweigh the risk of new-onset diabetes. ${ }^{32}$ Further, a retrospective cohort study including 16,027 patients with hypertension 
and dyslipidemia showed that those receiving fluvastatin, lovastatin, or rosuvastatin had a lower risk of new-onset diabetes (HR 0.45, 0.66, and 0.53 respectively; $P<0.0001$ for all), while those receiving pravastatin had a higher risk (HR 1.4; $P<0.0001$ ). Atorvastatin did show a higher risk for new-onset diabetes; however, when adjusted for age, sex, use of concomitant medications, and dose, this finding was no longer statistically significant (adjusted HR 1.15; $P=0.5465$ ). Hence, it has a dose-dependent effect on the risk of new-onset diabetes. Simvastatin did not increase the risk for new-onset diabetes (HR $1.1 ; P=0.3034$ ), thus it seemed to have a neutral effect. ${ }^{39}$

\section{Drug interactions}

The increased risk of myopathy/rhabdomyolysis is a major issue that should be considered when using Juvisync with other drugs. Table 2 indicates the most important drugs that may interact with Juvisync. ${ }^{16,19}$

\section{Special populations}

Precautions should be taken into consideration when using Juvisync in special populations. These are summarized in Table 3. ${ }^{16,19}$

\section{FDA-approved indications and potential uses}

Juvisync (sitagliptin and simvastatin) is approved by the FDA for use in patients who require treatment with both sitagliptin and simvastatin. Sitagliptin is indicated in adults with type $2 \mathrm{DM}$ as an adjunct to diet and exercise. Simvastatin is indicated in patients with an increased risk for atherosclerotic vascular disease due to hypercholesterolemia. It is used as an adjunct to diet when nonpharmacologic measures alone have

Table 2 Drug interactions associated with increased risk of myopathy/rhabdomyolysis

\begin{tabular}{ll}
\hline Interacting agents & $\begin{array}{l}\text { Prescribing } \\
\text { recommendations }\end{array}$ \\
\hline $\begin{array}{l}\text { Itraconazole, ketoconazole, posaconazole, } \\
\text { erythromycin, clarithromycin, telithromycin, } \\
\text { human immunodeficiency virus protease }\end{array}$ & $\begin{array}{l}\text { Contraindicated } \\
\text { with Juvisync }\end{array}$ \\
$\begin{array}{l}\text { inhibitors, nefazodone, gemfibrozil, } \\
\text { cyclosporine, danazol } \\
\text { Verapamil, diltiazem }\end{array}$ & \\
& Do not exceed \\
Amiodarone, amlodipine, ranolazine & Do not exceed \\
& $100 \mathrm{mg} / 20$ mg Juvisync daily \\
Grapefruit juice & Avoid large quantities of \\
& grapefruit juice (more than \\
& $950 \mathrm{~mL}$ daily) \\
\hline
\end{tabular}

Table 3 Special populations and Juvisync

\begin{tabular}{ll}
\hline Special populations & Comments \\
\hline Pediatric (aged $<18$ years) & $\begin{array}{l}\text { Safety and efficacy of Juvisync has not } \\
\text { been established in this population } \\
\text { Considering the higher risk of myopathy } \\
\text { and renal failure in this population, } \\
\text { caution is warranted upon using Juvisync } \\
\text { Use of Juvisync is contraindicated in this } \\
\text { Pregnancy/lactation }\end{array}$ \\
Renal impairment & $\begin{array}{l}\text { Juvisync is not recommended in } \\
\text { moderate or severe renal impairment } \\
\text { Jepatic impairment }\end{array}$ \\
& $\begin{array}{l}\text { Juvisync is contraindicated in patients } \\
\text { with active liver disease or persistent } \\
\text { unexplained elevated liver enzymes }\end{array}$ \\
\hline
\end{tabular}

been inadequate. In patients with existing CHD or at high risk of $\mathrm{CHD}$, it is indicated with diet to reduce $\mathrm{CHD}$-related mortality, risk of nonfatal myocardial infarction and stroke, and the need for coronary and noncoronary revascularization procedures. It is also indicated in primary hyperlipidemia to decrease LDL, total cholesterol, and triglycerides, and increase to high-density lipoprotein. ${ }^{16,19}$

On September 26, 2013, Merck, known as MSD outside the United States and Canada, said that the company will voluntarily discontinue distributing JUVISYNCTM tablets to pharmacies and wholesalers in the United States and Puerto Rico. This decision is for business reasons only and is not due to the efficacy or safety profile of JUVISYNC ${ }^{\text {TM }}$ or the individual components. Sitagliptin and simvastatin will continue to be available as separate medicines. JUVICOR ${ }^{\circledR}$, the brand name of the sitagliptin/simvastatin combination tablet outside the United States, will continue to be marketed and distributed outside the United States. JUVICOR is currently approved in 10 countries, and Merck plans to continue filing applications in additional countries. ${ }^{24}$

\section{Dosage, administration, and cost}

The available dosages in Juvisync are $100 \mathrm{mg} / 10 \mathrm{mg}$, $100 \mathrm{mg} / 20 \mathrm{mg}$, and $100 \mathrm{mg} / 40 \mathrm{mg}$ of sitagliptin/simvastatin once daily in the evening. The tablets should not be split, crushed, or chewed before swallowing. ${ }^{16}$ The recommended starting dose is $100 \mathrm{mg} / 40 \mathrm{mg}$ per day. If the patient is already taking simvastatin, Juvisync is initiated at the 100 mg dose of sitagliptin and the dose of simvastatin already being taken. If used as an adjunct to an insulin secretagogue or with insulin, the dose of the latter should be lowered to reduce the risk of hypoglycemia. Lipid levels should be measured 4 or more weeks after starting or titrating the dose. Juvisync is not recommended in patients with moderate or severe renal impairment or end-stage renal disease. However, 
it can be used in mild renal impairment (serum creatinine levels $\leq 1.7 \mathrm{mg} / \mathrm{dL}$ in men and $\leq 1.5 \mathrm{mg} / \mathrm{dL}$ in women). ${ }^{16}$

According to the manufacturer, the cost of Juvisync will be the same as the price of Januvia ${ }^{\mathrm{TM}}$ (sitagliptin) alone, which is $\$ 216$ for a one-month supply, so it is costeffective for patients requiring both medications. ${ }^{40}$ In addition, the patent for Juvisync will not end before April 2017, hence no generics would be seen until then.

\section{Conclusion}

Juvisync should be used in patients requiring both sitagliptin and simvastatin. Sitagliptin was noninferior to glipizide as add-on therapy but with lower rates of hypoglycemia and weight gain. In addition, although it was inferior to insulin, rates of hypoglycemia were significantly lower with sitagliptin. Thus, sitagliptin offers a worthy choice for diabetic patients to improve glycemic control with a lower risk of hypoglycemia and weight gain. Further, all trials have shown cardioprotective benefits of statin use in DM patients regardless of baseline lipid levels or existing cardiac disease. Both medications have also demonstrated an acceptable side effect profile. However, caution is needed when this product is coadministered with any drug that may increase the level of simvastatin to avoid the risks of myopathy and rhabdomyolysis.

\section{Disclosure}

The authors report no conflicts of interest in this work.

\section{References}

1. Ismail-Beigi F. Glycemic management of type 2 diabetes mellitus. N Engl J Med. 2012;366:1319-1327.

2. Nathan DM, Buse JB, Davidson MB, et al. Medical management of hyperglycemia in type 2 diabetes: a consensus algorithm for the initiation and adjustment of therapy: a consensus statement of the American Diabetes Association and the European Association for the Study of Diabetes. Diabetes Care. 2009;32:193-203.

3. Handelsman Y, Mechanick JI, Blonde L, et al. American Association of Clinical Endocrinologists Medical Guidelines for the Clinical Practice for Developing a Diabetes Mellitus Comprehensive Care Plan: executive summary. Endocr Pract. 2011;17 Suppl 2:287-302.

4. Ismail-Beigi F, Graven T, Benerji MA, et al. Effect of intensive treatment of hyperglycemia on microvascular outcomes in type 2 diabetes: an analysis of the ACCORD randomized trial. Lancet. 2010;376: 419-430.

5. Holman RR, Paul SK, Bethel M, et al. 10-year follow up of intensive glucose control in type 2 diabetes. N Engl J Med. 2008;358:2545-2559.

6. Patel A, MacMahon S, Chalmers J, et al. Intensive blood glucose control and vascular outcomes in patients with type 2 diabetes. $N$ Engl J Med. 2008;358:2560-2572.

7. Nauck MA, Meininger G, Sheng D, et al. Efficacy and safety of the dipeptidyl peptidase-4 inhibitor, sitagliptin, compared with the sulfonylurea, glipizide, in patients with type 2 diabetes inadequately controlled on metformin alone: a randomized, double-blind, non-inferiority trial. Diabetes Obes Metab. 2007;9:194-205.
8. Rosenstock J, Baron MA, Camisasca RP, et al. Efficacy and tolerability of initial combination therapy with vildagliptin and pioglitazone compared with component monotherapy in patients with type 2 diabetes. Diabetes Obes Metab. 2007;9:175-185.

9. American Diabetes Association. Standards of medical care in diabetes 2014. Diabetes Care. 2014;37 Suppl 1:S5-S13.

10. Expert Panel on Detection, Evaluation, and Treatment of High Blood Cholesterol in Adults. Executive summary of the third report of the National Cholesterol Education Program (NCEP) expert panel on detection, evaluation, and treatment of high blood cholesterol in adults (Adult Treatment Panel III). JAMA. 2001;285:2486-2497.

11. Irons BK, Kroon LA. Lipid management with statins in type 2 diabetes mellitus. Ann Pharmacother. 2005;39:1714-1719.

12. Colhoun HM, Betteridge J, Durrington PN, et al. Primary prevention of cardiovascular disease with atorvastatin in type 2 diabetes in the Collaborative Atorvastatin Diabetes Study (CARDS): multicenter randomized placebo-controlled trial. Lancet. 2004;364:685-696.

13. Heart Protection Study Collaborative Group. Effects on 11-year mortality and morbidity of lowering LDL cholesterol with simvastatin for about 5 years in 20536 high-risk individuals: a randomized controlled trial. Lancet. 2011;378:2013-2020.

14. Heart Protection Study Collaborative Group. MRC/BHF Heart Protection Study of cholesterol-lowering with simvastatin in 5963 people with diabetes: a randomized placebo controlled trial. Lancet. 2003;361: 2005-2016.

15. US Food and Drug Administration. FDA approves combination therapy Juvisync. Available from: http://www.fda.gov/NewsEvents/Newsroom/ PressAnnouncements/ucm274748.htm. Accessed January 5, 2015.

16. Juvisync [package insert]. Whitehouse Station, NJ, USA: Merck and Co Inc.; 2012.

17. Nathan D. Finding new treatments for diabetes - how many, how fast ... how good? N Engl J Med. 2007;356:437-440.

18. Miller SA, St Onge EL. Sitagliptin: a dipeptidyl peptidase IV inhibitor for the treatment of type 2 diabetes. Ann Pharmacother. 2006;40: $1336-1343$.

19. Merck and Co Inc. Juvisync: prescribing information. Available from: http://www.januvia.com/sitagliptin/januvia/hcp/juvisync/index.jsp. Accessed January 5, 2015.

20. Bergman AJ, Stevens C, Zhou Y, et al. Pharmacokinetic and pharmacodynamic properties of multiple oral doses of sitagliptin, a dipeptidyl peptidase-IV inhibitor: a double-blind, randomized, placebo-controlled study in healthy male volunteers. Clin Ther. 2006;28:55-72.

21. Bergman AJ, Cote J, Maes A, et al. Effect of sitagliptin on the pharmacokinetics of simvastatin. J Clin Pharmacol. 2009;49:483-488.

22. Hermansen K, Kipnes M, Fanurik D, et al. Efficacy and safety of the dipeptidyl peptidase-4 inhibitor, sitagliptin, in patients with type 2 diabetes mellitus inadequately controlled on glimepiride alone or on glimepiride and metformin. Diabetes Obes Metab. 2007;9: 733-745.

23. Harashima SI, Ogura M, Tanaka D, et al. Sitagliptin add-on to low dosage sulphonylureas: efficacy and safety of combination therapy on glycemic control and insulin secretion capacity in type 2 diabetes. Int J Clin Pract. 2012;66:465-476.

24. Merck Provides Update on Combination Medicine JUVISYNCTM (sitagliptin and simvastatin) Tablets. Available from: http://www. mercknewsroom.com/news/company-statements/merck-providesupdate-combination-medicine-juvisync-sitagliptin-and-simvastatin. Accessed January 5, 2014.

25. Aschner P, Chan J, Owens DR, et al. Insulin glargine versus sitagliptin in insulin-naive patients with type 2 diabetes mellitus uncontrolled on metformin (EASIE): a multicenter, randomized open-label trial. Lancet. 2012;379:2262-2269.

26. Lindholm LH. Major benefits from cholesterol lowering in patients with diabetes. Lancet. 2012;361:2000-2001.

27. Wanner C, Krane V, Marz W, et al. Atorvastatin in patients with type 2 diabetes mellitus undergoing hemodialysis. $N$ Engl $J$ Med. 2005;353:238-248. 
28. Keech A, Colquhoun D, Best J, et al. Secondary prevention of cardiovascular events with long-term pravastatin in patients with diabetes or impaired fasting glucose. Diabetes Care. 2003;26:2713-2721.

29. Law MR, Wald NJ, Rudnicka AR. Quantifying effect of statins on low density lipoprotein cholesterol, ischemic heart disease, and stroke: systematic review and meta-analysis. BMJ. 2003;326: 1423-1427.

30. Zhou Z, Rahme E, Pilote L, et al. Are statins created equal? Evidence from randomized trials of pravastatin, simvastatin, and atorvastatin for cardiovascular disease prevention. Am Heart J. 2006;151: 273-281.

31. Mills EJ, Wu P, Chong G, et al. Efficacy and safety of statin treatment for cardiovascular disease: a network meta-analysis of 170255 patients from 76 randomized trials. Q J Med. 2001;104:109-124.

32. Ridker PM, Pradhan A, MacFadyen JG, et al. Cardiovascular benefits and diabetes risks of statin therapy in primary prevention: an analysis from the JUPITER trial. Lancet. 2012;380:565-571.

33. US Food and Drug Administration. Information for healthcare professionals - acute pancreatitis and sitagliptin (marketed as Januvia or Janumet). Available from: http://www.fda.gov/Drug/DrugSafety/ PostmarketDrugSafetyInformationforPatientsandProviders/DrugSafety InformationforHealthcareProfessionals/ucm 183764.htm. Accessed January 5, 2015.
34. Engel SS, Williams-Herman DE, Golm GT, et al. Sitagliptin: review of preclinical and clinical data regarding incidence of pancreatitis. Int J Clin Pract. 2010;64:984-990.

35. Garc R, Chen W, Pendergrass M. Acute pancreatitis in type 2 diabetes treated with exenatide or sitagliptin: a retrospective observational pharmacy claims analysis. Diabetes Care. 2010;33:2349-2354.

36. Egan A, Colman E. Weighing the benefits of high-dose simvastatin against the risk of myopathy. $N$ Engl J Med. 2011;365:285-287.

37. Study of the Effectiveness of Additional Reductions in Cholesterol and Homocysteine (SEARCH) Collaborative Group. Intensive lowering of LDL cholesterol with $80 \mathrm{mg}$ versus $20 \mathrm{mg}$ simvastatin daily in 12064 survivors of myocardial infarction: a double-blind randomised trial. Lancet. 2010;376:1658-1669.

38. Kao DP, Kohrt HE, Kugler J. Case report: renal failure and rhabdomyolysis associated with sitagliptin and simvastatin use. Diabet Med. 2008;25:1229-1230.

39. Ma T, Tien L, Fang CL, et al. Statins and new-onset diabetes: a retrospective longitudinal cohort study. Clin Ther. 2012;34:1977-1983.

40. [No authors listed]. Sitagliptan and simvastatin (Juvisync). Med Lett Drugs Ther. 2011;53:89.
Vascular Health and Risk Management

\section{Publish your work in this journal}

Vascular Health and Risk Management is an international, peerreviewed journal of therapeutics and risk management, focusing on concise rapid reporting of clinical studies on the processes involved in the maintenance of vascular health; the monitoring, prevention and treatment of vascular disease and its sequelae; and the involvement of

\section{Dovepress}

metabolic disorders, particularly diabetes. This journal is indexed on PubMed Central and MedLine. The manuscript management system is completely online and includes a very quick and fair peer-review system, which is all easy to use. Visit http://www.dovepress.com/ testimonials.php to read real quotes from published authors. 